\title{
Haploinsufficiency of interferon regulatory factor 4 strongly protects against autoimmune diabetes in NOD mice
}

\author{
Satoru Akazawa $^{1}$ - Masakazu Kobayashi ${ }^{2}$ - Genpei Kuriya ${ }^{3}$ - Ichiro Horie ${ }^{1}$. \\ Liping $\mathrm{Yu}^{4}$ - Hironori Yamasaki ${ }^{2}$ - Minoru Okita ${ }^{5}$ Yuji Nagayama ${ }^{6}$. \\ Toshifumi Matsuyama ${ }^{7} \cdot$ Masoud Akbari $^{8} \cdot$ Katsuyuki Yui $^{8} \cdot$ Atsushi Kawakami $^{1}$. \\ Norio Abiru ${ }^{1}$
}

Received: 2 March 2015 / Accepted: 21 July 2015 / Published online: 14 August 2015

(C) Springer-Verlag Berlin Heidelberg 2015

\begin{abstract}
Aims/hypothesis Interferon regulatory factor (IRF) 4 plays a critical role in lymphoid development and the regulation of immune responses. Genetic deletion of IRF4 has been shown to suppress autoimmune disease in several mouse models, but its role in autoimmune diabetes in NOD mice remains unknown.

Methods To address the role of IRF4 in the pathogenesis of autoimmune diabetes in NOD mice, we generated IRF4knockout NOD mice and investigated the impact of the genetic deletion of IRF4 on diabetes, insulitis and insulin
\end{abstract}

Norio Abiru

abirun@nagasaki-u.ac.jp

1 Department of Endocrinology and Metabolism, Unit of Translational Medicine, Nagasaki University Graduate School of Biomedical Sciences, 1-7-1 Sakamoto, Nagasaki 852-8501, Japan

2 Center for Health and Community Medicine, Nagasaki University, Nagasaki, Japan

3 Department of Endocrinology and Metabolism, National Hospital Organization Nagasaki Medical Center, Nagasaki, Japan

4 Barbara Davis Center for Diabetes, University of Colorado Health Sciences Center, Aurora, CO, USA

5 Department of Locomotive Rehabilitation Science, Unit of Rehabilitation Sciences, Nagasaki University Graduate School of Biomedical Sciences, Nagasaki, Japan

6 Department of Molecular Medicine, Atomic Bomb Disease Institute, Nagasaki University, Nagasaki, Japan

7 Division of Cytokine Signaling, Department of Molecular Microbiology and Immunology, Nagasaki University Graduate School of Biomedical Sciences, Nagasaki, Japan

8 Division of Immunology, Department of Molecular Microbiology and Immunology, Nagasaki University Graduate School of Biomedical Sciences, Nagasaki, Japan autoantibody; the effector function of $\mathrm{T}$ cells in vivo and in vitro; and the proportion of dendritic cell subsets.

Results Heterozygous IRF4-deficient NOD mice maintained the number and phenotype of T cells at levels similar to NOD mice. However, diabetes and autoantibody production were completely suppressed in both heterozygous and homozygous IRF4-deficient NOD mice. The level of insulitis was strongly suppressed in both heterozygous and homozygous IRF4deficient mice, with minimal insulitis observed in heterozygous mice. An adoptive transfer study revealed that IRF4 deficiency conferred disease resistance in a gene-dosedependent manner in recipient NOD/severe combined immunodeficiency mice. Furthermore, the proportion of migratory dendritic cells in lymph nodes was reduced in heterozygous and homozygous IRF4-deficient NOD mice in an IRF4 dosedependent manner. These results suggest that the levels of IRF4 in T cells and dendritic cells are important for the pathogenesis of diabetes in NOD mice.

Conclusions/interpretation Haploinsufficiency of IRF4 halted disease development in NOD mice. Our findings suggest that an IRF4-targeted strategy might be useful for modulating autoimmunity in type 1 diabetes.

Keywords Autoimmunity $\cdot$ Dendritic cells $\cdot$ Interferon regulatory factor $4 \cdot$ NOD mice $\cdot$ T cells $\cdot$ Type 1 diabetes

$\begin{array}{ll}\text { Abbreviations } \\ \text { DC } & \text { Dendritic cell } \\ \text { FOXP3 } & \text { Forkhead box protein P3 } \\ \text { IAA } & \text { Insulin autoantibody } \\ \text { IRF } & \text { Interferon regulatory factor } \\ \text { mDC } & \text { Migratory dendritic cell } \\ \text { MFI } & \text { Mean fluorescent intensity } \\ \text { PE } & \text { Phycoerythrin }\end{array}$




$\begin{array}{ll}\text { SCID } & \text { Severe combined immunodeficiency } \\ \text { SPC } & \text { Splenocyte } \\ \text { TCR } & \text { T cell receptor } \\ \text { Th } & \text { Helper T cell } \\ \text { Treg } & \text { Regulatory T cell }\end{array}$

\section{Introduction}

Type 1 diabetes is an autoimmune disease that results from the autoreactive destruction of insulin-producing beta cells following mononuclear cell infiltration [1]. Studies of NOD mice (a well-characterised animal model of type 1 diabetes) have demonstrated that the beta cell destruction occurs as a consequence of a breakdown in immune regulation, i.e., activation of the innate immune system, and expansion of autoreactive $\mathrm{CD}^{+} \mathrm{T}$ cells, $\mathrm{CD}^{+} \mathrm{T}$ cells and autoantibody-producing $\mathrm{B}$ cells $[2,3]$. However, the precise mechanisms that control this autoimmune process are still not clearly understood.

Interferon regulatory factor (IRF) 4 is a transcriptional factor of the IRF family that regulates innate and adaptive immune responses [4]. In contrast to other IRFs, IRF4 is preferentially expressed in lymphocytes and its expression is not inducible by interferons, but rather by antigen receptormediated stimulation such as by plant lectins, CD3 or IgM crosslinking [5]. A series of reports have documented that IRF4 plays pleiotropic roles in lymphoid development and its immune response [6, 7]. At the molecular level, studies have suggested that IRF4, together with BATF (basic leucine zipper transcription factor ATF-like) and the activator protein-1 family member JUN, acts as a 'pioneer transcriptional factor' that prepares chromatin accessibility for the subsequent lineage-specific transcriptional factor and drives gene expression for the differentiation of effector T cells [8-10]. It has been documented that IRF4 is necessary for the differentiation of diverse effector $\mathrm{CD}^{+}{ }^{+} \mathrm{T}$ cell subsets, including helper T cell (Th) types Th2 [11-13], Th9 [14] and Th17 [6, 15, 16], follicular Th cells [17], the sustained effector function of cytotoxic T cells [18-20], the regulation of effector regulatory T cells (Tregs) [21], the series of developmental stages of B cells [17, 22-26] and the development and function of dendritic cells (DCs) [27-30].

IRF4 is thought to play a crucial role in the pathogenesis of autoimmune diseases, since the genetic deletion of IRF4 has been shown to abrogate several autoimmune diseases in mouse models, including experimental autoimmune encephalomyelitis [15], experimental colitis [31] and lupus nephritis [32]. Previous studies have suggested that a lack of IRF4 confers disease resistance due to failure of the specific differentiation of $\mathrm{CD}^{+}{ }^{+} \mathrm{T}$ cells, especially Th17 cells, in models of autoimmune diseases including MRL/lpr mice and NOD mice $[15,32-34]$. However, it is still unclear whether one or more specific Th subsets, such as Th17 cells, play a main role in autoimmune pathogenesis in type 1 diabetes, and we and others have reported that a lack of IL-17 does not alter diabetes susceptibility in NOD mice $[35,36]$.

Studies have indicated that IRF4 is essential for sustaining the differentiation of $\mathrm{CD}^{+} \mathrm{T}$ cells by regulating transcriptional factors that are crucial for effector generation (T-bet and Blimp-1) [18, 19]. Furthermore, the expression of IRF4, which is regulated by antigen-T cell receptor (TCR) affinity, has also been reported to be required for the metabolic function and migratory behaviour of activated $\mathrm{CD}^{+} \mathrm{T}$ cells in a dose-dependent manner [20]. We therefore hypothesised that the dosage of IRF4 expression regulates autoimmune pathogenesis in NOD mice, mediated by autoreactive $\mathrm{CD}^{+}$and $\mathrm{CD}^{+} \mathrm{T}$ cells.

To this end, we generated heterozygous and homozygous IRF4-deficient NOD mice and evaluated the influence of the genetic modification of IRF4 on the development of autoimmune diabetes, and on the effector function of $\mathrm{CD}^{+}$and $\mathrm{CD}^{+} \mathrm{T}$ cells in vivo and in vitro.

\section{Methods}

Mice NOD mice and NOD/severe combined immunodeficiency (SCID) mice were purchased from Clea Japan (Tokyo, Japan). IRF4-deficient mice had been previously generated [37]. These mice were maintained by breeding at the Laboratory Animal Center for Animal Research at Nagasaki University under specific pathogen-free conditions. Only female mice were used in this study.

Establishment of IRF4-deficient NOD mice IRF4-deficient mice were backcrossed with NOD mice for 15 successive generations. These mice were selected by a PCR analysis of tail DNA, as previously described [37, 38]. An analysis of the microsatellite markers of the diabetes susceptibility (Idd1-14) loci by PCR of the tail DNA, as previously described [38], showed that the mice were homozygous for all of the NOD alleles. Genotyping of chromosome 13 confirmed that the NOD/B6/129 polymorphic markers D13Mit80 (8.7 cM from IRF4 loci), D13Mit218 (21.8 cM), D13Mit163 (25.4 cM), D13Mit84 (25.7 cM) and D13Mit61 (Idd14) (41.0 cM) were all derived from the NOD background.

Homozygous IRF4-deficient (Irf4 ${ }^{--}$), heterozygous IRF4deficient $\left(\operatorname{Irf4} 4^{+/}\right)$and wild-type (WT) NOD mice were established by intercrossing heterozygotes of the 15 th generation. All animal experiments described in this study were approved by the institutional animal experimentation committee and were conducted in accordance with the Guidelines for Animal Experimentation.

Monitoring for spontaneous diabetes Mouse blood glucose levels were monitored for spontaneous diabetes using the 
OneTouch Ultra blood glucose monitoring system (Johnson \& Johnson, Tokyo, Japan). Monitoring was conducted weekly when the mice were 12-20 weeks old and then every other week from 20 to 50 weeks of age. Monitoring was terminated when the mice became moribund. Mice with blood glucose levels of more than $13.9 \mathrm{mmol} / \mathrm{l}$ for two consecutive measurements were considered diabetic.

Measurement of serum IgG and insulin autoantibodies We performed an ELISA to measure IgG in the serum of mice at 4 weeks of age using the Mouse IgG ELISA Quantitation Set (Bethyl Laboratories, Montgomery, TX, USA). We evaluated the levels of insulin autoantibody (IAA) in serum using a 96-well filtration plate micro IAA assay, as previously described [39].

Histology Pancreatic sections from 18-week-old mice were histologically analysed by staining paraffin-embedded samples with haematoxylin and eosin. A minimum of 30 islets from each mouse were evaluated under a microscope by two different observers. The severity of insulitis was scored as follows: 0 , no lymphocytic infiltration; 1 , lymphocytic infiltration occupying $<25 \%$ of the total islet cell area; 2 , lymphocytic infiltration occupying $25-50 \%$ of the total islet cell area; 3 , lymphocytic infiltration occupying $50-75 \%$ of the total islet cell area; 4 , lymphocytic infiltration occupying $>75 \%$ of the total islet cell area, or small retracted islets.

Adoptive transfer experiments $\mathrm{CD} 4^{+} \mathrm{CD} 25^{-} \mathrm{T}$ cells or $\mathrm{CD} 8^{+}$ $\mathrm{T}$ cells were purified from the spleens of 10- to 12-week-old prediabetic $I r f 4^{-/}, \operatorname{Irf4}{ }^{+/-}$and WT NOD mice using magnetic bead cell sorting (Miltenyi Biotech, Auburn, CA, USA). The purity of the $\mathrm{CD}^{+} \mathrm{CD} 25^{-}$and $\mathrm{CD} 8^{+}$T cells was at least $92 \%$ and $98 \%$, respectively, as confirmed by flow cytometry analysis. Purified $\mathrm{CD}^{+} \mathrm{CD} 25^{-}\left(1.0 \times 10^{7}\right)$ and $\mathrm{CD}^{+}\left(0.5 \times 10^{7}\right) \mathrm{T}$ cells were combined and i.p. injected into 10 -week-old NOD/SCID mice, and the mice were then monitored for blood glucose twice weekly after the adoptive transfer.

Flow cytometric analysis Single-cell suspensions were prepared from mouse spleens, pancreatic lymph nodes and inguinal lymph nodes. Red blood cells were lysed in ammonium chloride buffer. For surface staining, cells were stained for $20 \mathrm{~min}$ with the corresponding fluorescent-labelled or biotinconjugated antibodies against surface molecules: CD3e (1452C11), CD4 (GK1.5), CD8 (53-6.7), B220 (RA3-6B2), CD44 (IM7), CD62L (MEL-14), I-A ${ }^{\mathrm{g} 7}\left(\mathrm{I}-\mathrm{A}^{\mathrm{k}}, 10-3.6\right)$ and CD11c (N418).

For intracellular IRF4 staining of T cells, splenocytes (SPCs) were stimulated with plate-bound anti-CD3 (BD Biosciences/BD Pharmingen, San Diego, CA, USA) and soluble anti-CD28 (37.51) $(2 \mu \mathrm{g} / \mathrm{ml})$ (eBioscience, San Diego, CA, USA) for $36 \mathrm{~h}$ and then stained with phycoerythrin
(PE)-conjugated anti-IRF4 (3E4) antibodies. For the intracellular cytokine staining, SPCs were stimulated with $50 \mathrm{ng} / \mathrm{ml}$ phorbol 12-myristate 13-acetate (PMA) and $500 \mathrm{ng} / \mathrm{ml}$ ionomycin (both from Sigma, St Louis, MO, USA) in the presence of $2 \mu \mathrm{M}$ monensin for $5 \mathrm{~h}$. Thereafter, the cells were stained with allophycocyanin-conjugated anti-CD4, followed by intracellular staining with PE-Cy7-conjugated anti-IL-17 (eBio17B7) and PerCP-Cy5.5-conjugated anti-IFN- $\gamma$ (XMG1.2) antibodies (all from eBioscience). For intracellular IRF4 staining of DCs, cells were directly stained without culture.

For intracellular staining of granzyme B and perforin, purified $\mathrm{CD}^{+} \mathrm{T}$ cells were activated with plate-bound antiCD3 and anti-CD28 for $48 \mathrm{~h}$, followed by incubation with recombinant mouse IL-2 (100 U/ml; eBioscience) for $72 \mathrm{~h}$. Before intracellular staining, the activated $\mathrm{CD} 8^{+} \mathrm{T}$ cells were re-stimulated with PMA and ionomycin in the presence of monensin during the final $5 \mathrm{~h}$. Thereafter, the cells were stained with PE-conjugated anti-granzyme B (16G6) and FITC-conjugated anti-perforin (eBioOMAK-D) antibodies. For intracellular forkhead box protein P3 (FOXP3) staining, cells were stained with FITC-conjugated anti-CD4 and PE-conjugated anti-CD25 (PC61), followed by intracellular FOXP3 staining with PE-Cy5-conjugated anti-FOXP3 (FJK16s). All cells were analysed on a FACSCanto II flow cytometry system using FACSDiva software (BD Biosciences).

Statistical analysis Data are expressed as means (SD). Group differences were analysed using Student's $t$ test. Differences between Kaplan-Meier survival curves were evaluated by the log-rank test, using SPSS II software for Windows (SPSS, Chicago, IL, USA). $p$ values of less than 0.05 were considered significant.

\section{Results}

IRF4 expression on $T$ cells and DCs, lymphocyte numbers and IgG production We first assessed the expression of IRF4 in $\mathrm{CD}^{+}$and $\mathrm{CD} 8^{+} \mathrm{T}$ cells after TCR stimulation and in DCs without stimulation. T cells and DCs derived from Irf4 ${ }^{-/}$ NOD mice were used as negative controls. The expression levels of IRF4 in T cells and DCs derived from $\mathrm{Irf}_{4}{ }^{+-} \mathrm{NOD}$ mice were almost half those from WT NOD mice (mean fluorescent intensity [MFI] of $\mathrm{CD}^{+} \mathrm{T}$ cells: $3,221 \pm 71$ in WT vs $1,806 \pm 209$ in $\operatorname{Irf4} 4^{+/-}$; $\mathrm{CD}^{+}$T cells: $2,255 \pm 234$ in WT vs $1,271 \pm 192$ in $\operatorname{Irf} 4^{+-}$; DCs: $1,014 \pm 83$ in WT vs $720 \pm 70$ in Irf $4^{++-}$; all $\left.p<0.01\right)$ (Fig. 1a-c).

Since IRF4 knockout mice have been reported to have lymphadenopathy [37], we assessed the cell numbers of lymphocyte subsets in SPCs and pancreatic lymph nodes. Flow cytometric analysis revealed that, compared with WT NOD mice of the same age, 12-week-old $\operatorname{Irf} 4^{-/}$NOD mice had 
a

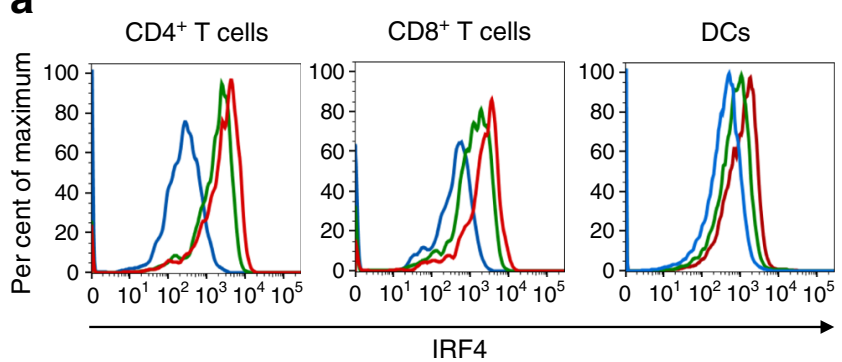

b
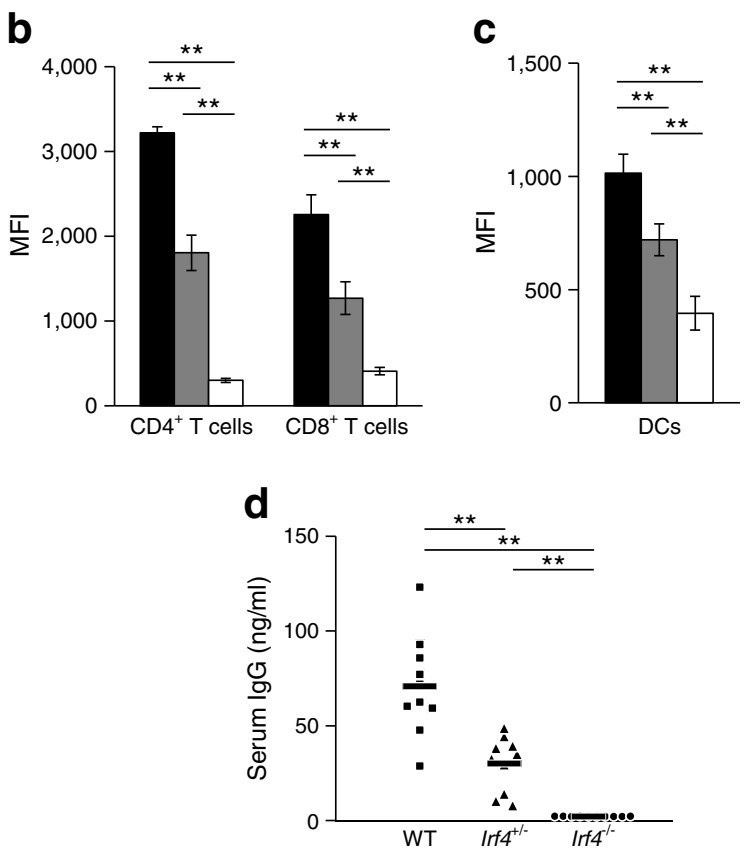

Fig. 1 (a) Expression of IRF4 in $\mathrm{CD}^{+} \mathrm{T}$ cells, $\mathrm{CD} 8^{+} \mathrm{T}$ cells and DCs. SPCs from WT (red), $\mathrm{Irf4}^{+/}$(green) and $\mathrm{Irf4}^{-/}$(blue) NOD littermates were stimulated with anti-CD3/CD28 monoclonal antibodies and stained for CD4, CD8 and IRF4. IRF4 profiles of $\mathrm{CD}^{+}$and $\mathrm{CD}^{+}$cells are shown (left and centre). SPCs were stained for CD11 c/I-A $\mathrm{A}^{\mathrm{g} 7}$, and IRF4 profiles of CD11 $\mathrm{c}^{+} \mathrm{I}-\mathrm{A}^{\mathrm{g} 7+}$ cells are shown (right). MFI of IRF4 staining in (b) $\mathrm{CD}^{+}$and $\mathrm{CD} 8^{+} \mathrm{T}$ cells and (c) DCs derived from WT (black bars), $\mathrm{Irf4}^{+/}$(grey bars) and $\mathrm{Irf4}^{-/}$NOD littermates (white bars). Data are means \pm SD $(n=3-5)$. (d) Serum IgG from female WT, Irf4 ${ }^{+/}$and $\operatorname{Irf4^{-/}}$ NOD littermates ( $n=10$ per group) was evaluated with ELISA. $* * p<0.01$

significantly increased numbers of lymphocytes, including $\mathrm{CD}^{+}, \mathrm{CD}^{+}$and $\mathrm{CD} 8^{+} \mathrm{T}$ cells and $\mathrm{B}$ cells, but a slightly increased proportion of $\mathrm{CD} 4^{+} \mathrm{T}$ cells and a decreased proportion of $\mathrm{CD}^{+} \mathrm{T}$ cells (Table 1). In contrast, $\mathrm{Irf4}{ }^{+/-}$NOD mice showed normal lymphocyte subset distribution and cellularity.

We also found that IRF4 deficiency lowered the serum concentrations of $\mathrm{IgG}$ in a gene-dose-dependent manner in NOD mice $(p<0.01)$ (Fig. 1d).

Diabetes, insulitis and IAA levels in IRF4-deficient NOD mice To study the role of IRF4 in the pathogenesis of autoimmune diabetes in NOD mice, we compared the incidence of diabetes from 12 to 50 weeks of age, the level of insulitis at
18 weeks and the level of IAA at 12 weeks among female

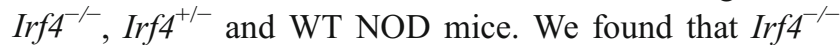
NOD mice were completely protected from the development of insulitis/diabetes, whereas littermate WT NOD mice showed the normal development of insulitis/diabetes as usually observed in our colony. Importantly, heterozygous IRF4 deficiency completely suppressed the development of diabetes, although minimal insulitis was observed in a small fraction of mice (Fig. 2a,b). IAA expression was absent in both Irf4 ${ }^{+/-}$and $I r f 4^{-/}$NOD mice (Fig. 2c). All of the $I r f 4^{-/}$NOD mice, but not the $\operatorname{Irf4^{+/-}}$ mice, became moribund after 40 weeks of age for unknown reasons. This type of early death is also sometimes observed in $\mathrm{Irf4}^{-/-}$non-NOD mice, and it is unlikely that their deaths are associated with autoimmunity.

Adoptive transfer study with Treg-depleted effector T cells into NOD/SCID mice Type 1 diabetes has been considered to be a $\mathrm{T}$ cell-mediated disease. The disease resistance induced by IRF4 deficiency may be due to attenuation of the effector function of T cells in NOD mice. To assess the effector function of IRF4-deficient $\mathrm{T}$ cells, we compared the development of adoptively transferred diabetes in recipient NOD/SCID mice that received combined Treg-depleted $\mathrm{CD} 4^{+} \mathrm{CD} 25^{-} \mathrm{T}$ cells $\left(1.0 \times 10^{7}\right)$ and $\mathrm{CD} 8^{+} \mathrm{T}$ cells $\left(0.5 \times 10^{7}\right)$ purified from SPCs of prediabetic $\operatorname{Irf4^{-/}}{ }^{-}, \operatorname{Irf} 4^{+/-}$and WT NOD mice. Two-thirds (8/12) of the recipient mice transferred with effector T cells from WT NOD mice rapidly developed diabetes, as expected, while the mice with $\mathrm{Irft}^{-/} \mathrm{T}$ cells did not develop diabetes until 50 days post-transfer (Fig. 3, $p<0.05$ ). The $25 \%$ of mice (3/12) transferred with T cells from Irf4 ${ }^{+/-}$NOD mice developed diabetes, but with a significant reduction in diabetes incidence compared with mice transferred with WT T cells (Fig. 3, $p<0.05$ ).

To investigate the respective effector functions of IRF4deficient $\mathrm{CD}^{+}{ }^{+}$and $\mathrm{CD} 8^{+} \mathrm{T}$ cells, we conducted an adoptive transfer experiment with combined $\mathrm{CD} 4^{+} \mathrm{CD} 25^{-}$and $\mathrm{CD} 8^{+} \mathrm{T}$ cell subsets alternately derived from $\mathrm{Irf4}^{--}$and WT NOD mice. Diabetes development was suppressed to $11 \%(1 / 9)$ in mice transferred with $\mathrm{Irf4}^{-/} \mathrm{CD} 4 / \mathrm{Irf4}^{+/+} \mathrm{CD} 8$ subsets compared with mice with both subsets from WT NOD mice (Fig. 3, $p<0.05$ ). No diabetes was observed in mice with Irf4 ${ }^{+/+} \mathrm{CD} 4 / \mathrm{Irf4} 4^{-/} \mathrm{CD} 8$ subsets (Fig. 3). Histological analysis revealed that the severity of insulitis was not significantly different between recipient mice with $\mathrm{Irf4}^{-/-} \mathrm{CD} 4 / \mathrm{Irf} 4^{+/+} \mathrm{CD} 8$ and those with $\operatorname{Irf} 4^{+/+} \mathrm{CD} 4 / \mathrm{Irf}_{4}{ }^{--} \mathrm{CD} 8$ subsets (mean insulitis score at 50 days after transfer: $2.02 \pm 1.66$ in four mice with $\operatorname{Irf} 4^{-/-} \mathrm{CD} 4 / / r f 4^{+/+} \mathrm{CD} 8$ vs $2.14 \pm 0.77$ in three mice with Irf $\left.4^{+/+} \mathrm{CD} 4 / \mathrm{Irf} 4^{-/} \mathrm{CD} 8, p=0.9\right)$. These results indicate that IRF4 plays a crucial role in effector functions in not only $\mathrm{CD}^{+} \mathrm{T}$ cells, but also $\mathrm{CD} 8^{+} \mathrm{T}$ cells in NOD mice.

Flow cytometric analysis for $\mathrm{CD}^{+}, \mathrm{CD8}^{+} \mathrm{T}$ cells and $\mathrm{DCs}$ in IRF4-deficient NOD mice Because IRF4 affects the 
Table 1 Number of T cells $\left(\mathrm{CD} 4^{+}, \mathrm{CD} 8^{+}\right)$and B cells in SPCs and pancreatic lymph nodes

\begin{tabular}{|c|c|c|c|c|c|}
\hline \multirow[t]{2}{*}{ Subgroup } & \multirow[t]{2}{*}{ Total cell number, $\times 10^{6}$} & \multicolumn{4}{|c|}{ Cell number, $\times 10^{6}(\%$ of total cells) } \\
\hline & & $\mathrm{CD}^{+}$ & $\mathrm{CD}^{+}$ & $\mathrm{CD}^{+}$ & $\mathrm{B} 220^{+}$ \\
\hline \multicolumn{6}{|l|}{ SPCs } \\
\hline WT & $15.8 \pm 4.5$ & $7.0 \pm 1.7(44.4 \pm 2.4)$ & $4.6 \pm 1.3(28.9 \pm 1.6)$ & $1.9 \pm 0.3(12.5 \pm 1.5)$ & $4.9 \pm 2.0(30.3 \pm 4.4)$ \\
\hline $\operatorname{Irf4} 4^{+/}$ & $20.1 \pm 9.1$ & $8.9 \pm 4.1(43.9 \pm 2.9)$ & $5.7 \pm 2.5(28.6 \pm 3.0)$ & $2.4 \pm 1.2(11.8 \pm 0.7)$ & $6.4 \pm 3.2(31.6 \pm 3.7)$ \\
\hline $\operatorname{Irf4^{-1}}$ & $104.0 \pm 52.1^{* *}$ & $46.4 \pm 23.7 * *(44.7 \pm 4.4)$ & $35.1 \pm 17.3 * *(34.2 \pm 3.3 *)$ & $7.4 \pm 4.2^{*}\left(6.9 \pm 1.6^{* *}\right)$ & $33.3 \pm 13.0^{* *}(33.7 \pm 4.6)$ \\
\hline \multicolumn{6}{|c|}{ Pancreatic lymph nodes } \\
\hline WT & $0.37 \pm 0.16$ & $0.30 \pm 0.14(81.9 \pm 3.5)$ & $0.21 \pm 0.10(57.6 \pm 5.9)$ & $0.08 \pm 0.04(21.0 \pm 1.8)$ & $0.04 \pm 0.02(10.3 \pm 3.6)$ \\
\hline $\operatorname{Irf4} 4^{+/}$ & $0.66 \pm 0.43$ & $0.56 \pm 0.38(84.4 \pm 5.1)$ & $0.40 \pm 0.26(60.5 \pm 4.5)$ & $0.14 \pm 0.10(21.0 \pm 1.6)$ & $0.06 \pm 0.03(10.6 \pm 2.8)$ \\
\hline $\operatorname{Irf4^{-1-}}$ & $7.26 \pm 2.83 * *$ & $6.20 \pm 2.34 * *(85.2 \pm 9.6)$ & $4.95 \pm 1.81 * *(68.4 \pm 5.1 *)$ & $1.07 \pm 0.64 * *(14.4 \pm 6.5)$ & $0.81 \pm 0.79(11.2 \pm 7.6)$ \\
\hline
\end{tabular}

Data are means $\pm \mathrm{SD}$

$* p<0.05, * * p<0.01$ vs WT

effector function of $\mathrm{CD} 8^{+}$as well of $\mathrm{CD} 4^{+} \mathrm{T}$ cells, we evaluated the phenotypes of each $\mathrm{T}$ subset. We first determined the expression of surface molecules, identifying memory and naive $\mathrm{T}$ cells, CD44 and CD62L, and the Treg population on $\mathrm{CD}^{+} \mathrm{T}$ cells without stimulation. We found that $\operatorname{Irf4^{-/-}}$ NOD mice did not maintain $T$ cell homeostasis, and that the populations of memory and naive $\mathrm{T}$ cells were significantly reduced in $\mathrm{Irf}^{-/}$compared with WT NOD mice. However, the populations of memory and naive T cells in $\mathrm{Irft}^{+/-}$mice were equivalent to those in WT NOD mice (Fig. $4 \mathrm{a}-\mathrm{c}, \mathrm{g}$ ). With regard to Tregs, the percentages of $\mathrm{CD} 4^{+} \mathrm{CD} 25^{+} \mathrm{FOXP} 3^{+} \mathrm{T}$ cells were significantly reduced in $\mathrm{Irf4}^{-/-}$and $\mathrm{Irft}^{+/-} \mathrm{NOD}$ mice in a gene-dose-dependent manner $(9.7 \pm 0.8 \%$ in WT vs $7.8 \pm 0.4 \%$ in $\operatorname{Irf4}^{+--}$and $4.3 \pm 0.5 \%$ in $\operatorname{Irf4}^{-/-}$NOD mice, $p<0.01$ ) (Fig. $4 \mathrm{~d}-\mathrm{f}, \mathrm{h})$.

We next evaluated cytokine expression in $\mathrm{CD}^{+} \mathrm{T}$ cells by intracellular staining after stimulation. As previously observed in $\mathrm{Irf4}^{-\alpha} \mathrm{C} 57 \mathrm{BL} / 6$ mice [15], the percentage of IL-17-producing $\mathrm{CD}^{+} \mathrm{T}$ cells was significantly reduced in stimulated SPCs derived from $\mathrm{Irft}^{4^{--}}$NOD mice, while the percentages of IL-17-positive cells from $\mathrm{Irf4}^{+/-}$NOD mice were almost equal to those from WT NOD mice. In contrast, the percentages of IFN- $\gamma$-producing cells did not significantly differ among the three groups (Fig. 5a-c,g). We also assessed the effector molecules of cytotoxic $T$ cells, granzyme $\mathrm{B}$ and perforin, in purified $\mathrm{CD}^{+} \mathrm{T}$ cells after TCR stimulation followed by incubation with IL-2. The production of granzyme B and perforin were severely impaired in $\mathrm{Irf4}^{-/}$, but not in $\mathrm{Irf4} 4^{+/}, \mathrm{CD}^{+} \mathrm{T}$ cells compared with WT $\mathrm{CD}^{+} \mathrm{T}$ cells (Fig. $5 \mathrm{~d}-\mathrm{f}, \mathrm{h}$ ).

Because IRF4 also plays an important role in the development and function of dendritic subsets, we next evaluated DCs in NOD mice. The proportion of $\mathrm{CD}^{+} \mathrm{DCs}$ in the spleen was reduced in $\mathrm{Irf}^{-/-}$compared with WT NOD mice, as has been previously reported in $\mathrm{Irft}^{-/}$non-NOD mice [27]. This reduction was not, however, significant in $\mathrm{Irf4}^{+/-}$NOD mice (Fig. 6a-f,j). In the lymph nodes, the proportion of migratory (m)DC (MHC-II ${ }^{\text {hi }} \mathrm{CD} 11 \mathrm{c}^{\mathrm{int}}$ ) was reduced in $\mathrm{Irft}^{-/}$compared with WT NOD mice, as has also been reported in $\mathrm{Irf4}^{-/-}$nonNOD mice $[29,30]$. Interestingly, the proportion of mDCs in

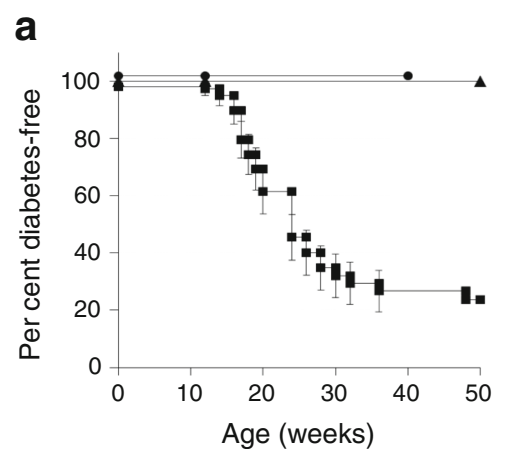

Fig. 2 Diabetes, insulitis and IAAs in WT, $\operatorname{Irf4}{ }^{+/}$and $\mathrm{Irf}_{4}{ }^{-/}$NOD mice. (a) Incidence of diabetes in WT (squares, $n=40$ ), $\operatorname{Irf}^{+}{ }^{-}$(triangles, $n=30$ ) and $\mathrm{Irf4}^{-/}$(circles, $n=40$ ) NOD littermates. (b) Severity of insulitis in WT, Irf4 $4^{+/}$and $\operatorname{Irf4}^{-1}$ NOD littermates at 18 weeks of age $(n=5$ per group). Insulitis levels: 0 (white), 1 (light grey), 2 (dark grey), 3 b
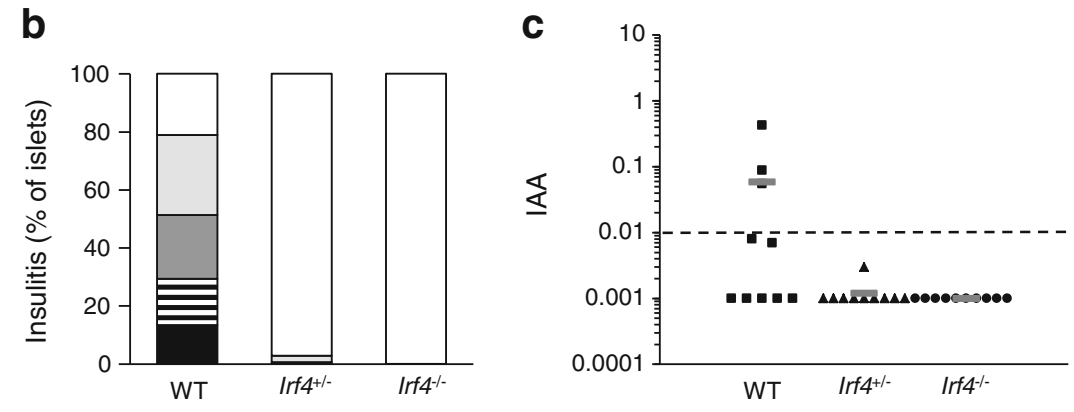

(horizontal stripes) and 4 (black). (c) Levels of serum IAA in WT, $\mathrm{Irf4}^{+/}$and $\mathrm{Irf} 4^{-/}$NOD littermates at 12 weeks of age ( $n=10$ per group). The index value of 0.01 was applied as the cut-off limit. Each square/ triangle/circle represents an individual animal. Dark grey horizontal lines indicate the mean 


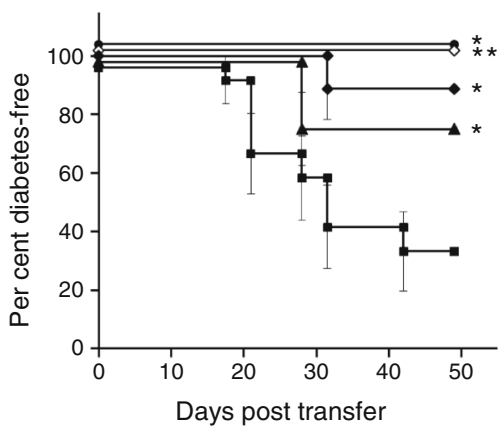

Fig. 3 Adoptive transfer of purified $\mathrm{CD} 4^{+} \mathrm{CD} 25^{-} \mathrm{T}$ cells $\left(1.0 \times 10^{7}\right)$ and $\mathrm{CD}^{+} \mathrm{T}$ cells $\left(0.5 \times 10^{7}\right)$ from WT, $\operatorname{Irf}^{+/}$and $\operatorname{Irf4}^{-/}$NOD mice into NOD/SCID mice. Recipient mice were divided into five groups according to the combination of transfer subsets: WT CD4 ${ }^{+} \mathrm{CD} 25^{-}$T cells $+\mathrm{WT}$ $\mathrm{CD} 8^{+} \mathrm{T}$ cells $(n=12$, squares $) ; \mathrm{Irf4}{ }^{+/-} \mathrm{CD} 4^{+} \mathrm{CD} 25^{-} \mathrm{T}$ cells + Irf $4^{+/} \mathrm{CD} 8^{+}$ $\mathrm{T}$ cells $\left(n=12\right.$, triangles); Irf4 ${ }^{--} \mathrm{CD} 4^{+} \mathrm{CD} 25^{-} \mathrm{T}$ cells $+\operatorname{Irf} 4^{--} \mathrm{CD} 8^{+} \mathrm{T}$ cells $\left(n=5\right.$, circles); $\mathrm{Irf}^{-/-} \mathrm{CD} 4^{+} \mathrm{CD} 25^{-} \mathrm{T}$ cells $+\mathrm{WT} \mathrm{CD} 8^{+} \mathrm{T}$ cells ( $n=9$, black diamonds); and WT $\mathrm{CD} 4^{+} \mathrm{CD} 25^{-} \mathrm{T}$ cells + Irf $4^{--} \mathrm{CD} 8^{+} \mathrm{T}$ cells $\left(n=9\right.$, white diamonds). Error bars: SE. ${ }^{*} p<0.05,{ }^{*} p<0.01$ using the log-rank test vs the subgroup that received both subsets from WT NOD mice
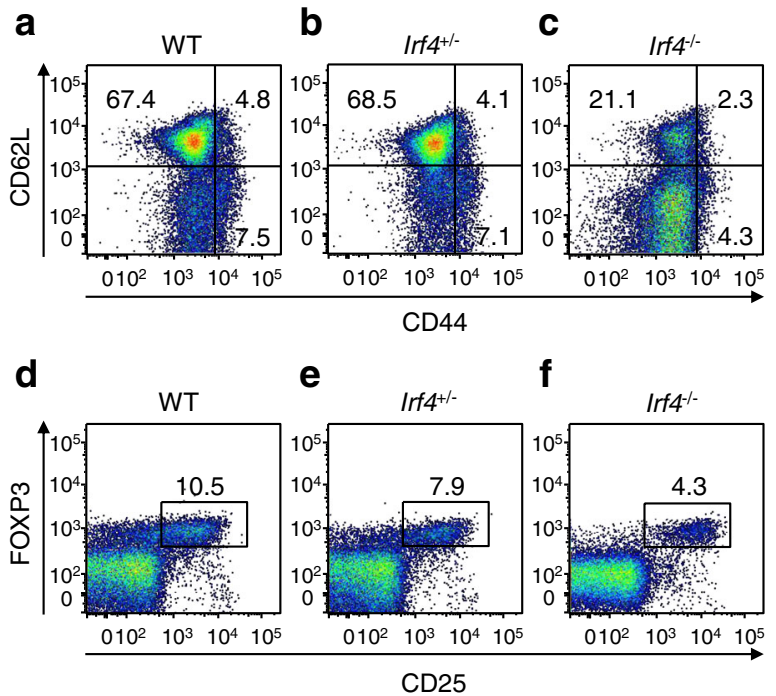

g
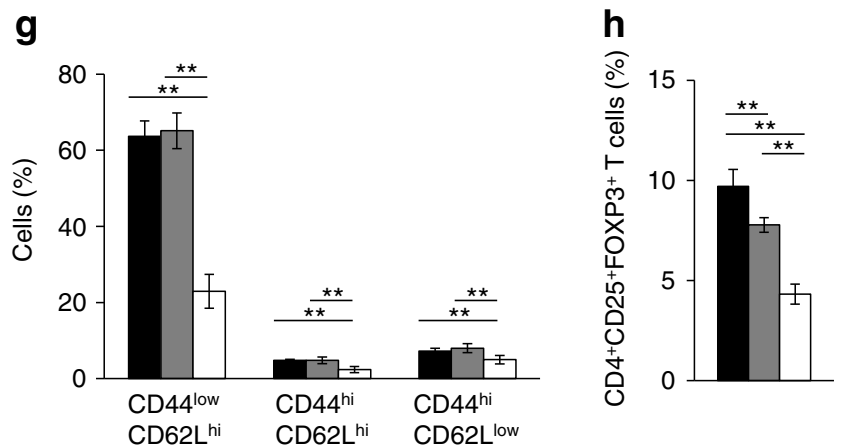

Fig. 4 Activation markers and $\mathrm{FOXP} 3^{+} \mathrm{CD} 25^{+}$cells in $\mathrm{CD} 4^{+} \mathrm{T}$ cells. Representative staining of $\mathrm{CD}^{+}$SPCs for $(\mathbf{a}-\mathbf{c}) \mathrm{CD} 44$ and CD62L and (d-f) CD25 and FOXP3. Quantification of (g) CD44 ${ }^{\text {low }}{ }^{2 D} 62 \mathrm{~L}^{\text {hi }}$, CD $44{ }^{\mathrm{hi}} \mathrm{CD} 62 \mathrm{~L}^{\mathrm{hi}}$ and $\mathrm{CD} 44{ }^{\mathrm{hi}} \mathrm{CD} 62 \mathrm{~L}^{\mathrm{low}}$ cells and (h) $\mathrm{CD}^{+} \mathrm{CD} 25^{+} \mathrm{FOXP}^{+}$cells in WT (black bars), $\mathrm{Irf4}{ }^{+/-}$(grey bars) and $\operatorname{Irf4}^{-/-}$(white bars) NOD littermates. Data are means \pm SD $(n=5)$. $* * p<0.01$
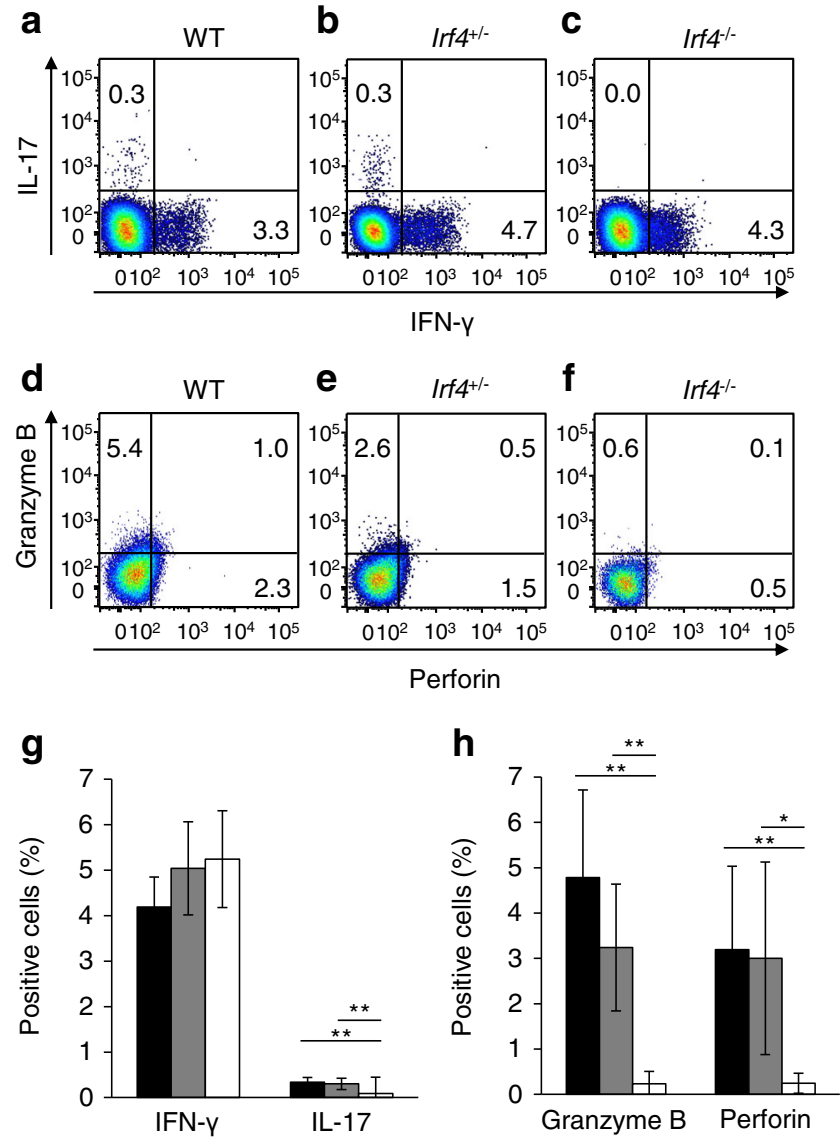

Fig. $5 \mathrm{IFN}-\gamma^{+} / \mathrm{IL}-17^{+}$cells in $\mathrm{CD} 4^{+} \mathrm{T}$ cells and effector molecules in $\mathrm{CD}^{+} \mathrm{T}$ cells. (a-c) Representative staining of $\mathrm{CD}^{+}$SPCs for intracellular IFN- $\gamma$ and/or IL-17. (d-f) Purified $C D 8^{+}$T cells were stimulated as mentioned in the Methods section. Representative data for the intracellular expression of granzyme B and perforin are shown. Quantification of (g) IFN- $\gamma$ - and IL-17-positive cells and (h) granzyme B- and perforinpositive cells in WT (black bars), $\operatorname{Irf4}^{+/-}$(grey bars) and $\operatorname{Irf4^{-/}}$ (white bars) NOD littermates. Data are means $\pm \mathrm{SD}(n=5) .{ }^{*} p<0.05, * * p<0.01$

the lymph nodes of $I r f 4^{+/-}$NOD mice was intermediate between the other two strains, suggesting that the $\mathrm{mDC}$ proportion is dependent on the dose of the Irf4 gene (Fig. $6 \mathrm{~g}-\mathrm{i}, \mathrm{k}$ ).

\section{Discussion}

In this study, we determined the impact of the genetic deletion of IRF4 in NOD mice on the pathogenesis of type 1 diabetes. We found that $I r f 4^{--}$NOD mice were completely protected from spontaneous diabetes, insulitis and autoantibody production, indicating that IRF4 is a crucial transcriptional factor in the development of autoimmune diabetes in NOD mice, as has been reported for other autoimmune diseases [15, 31-33]. Compared with WT NOD mice, the spleens and lymph nodes of $\mathrm{Irf4}^{-/}$NOD mice had phenotypes of lymphadenopathy, including larger size, an increased number of $\mathrm{T}$ and $\mathrm{B}$ cells and dysregulated naive/memory $\mathrm{CD} 4^{+} \mathrm{T}$ cell populations. Severe hypogammaglobulinaemia was also observed in 

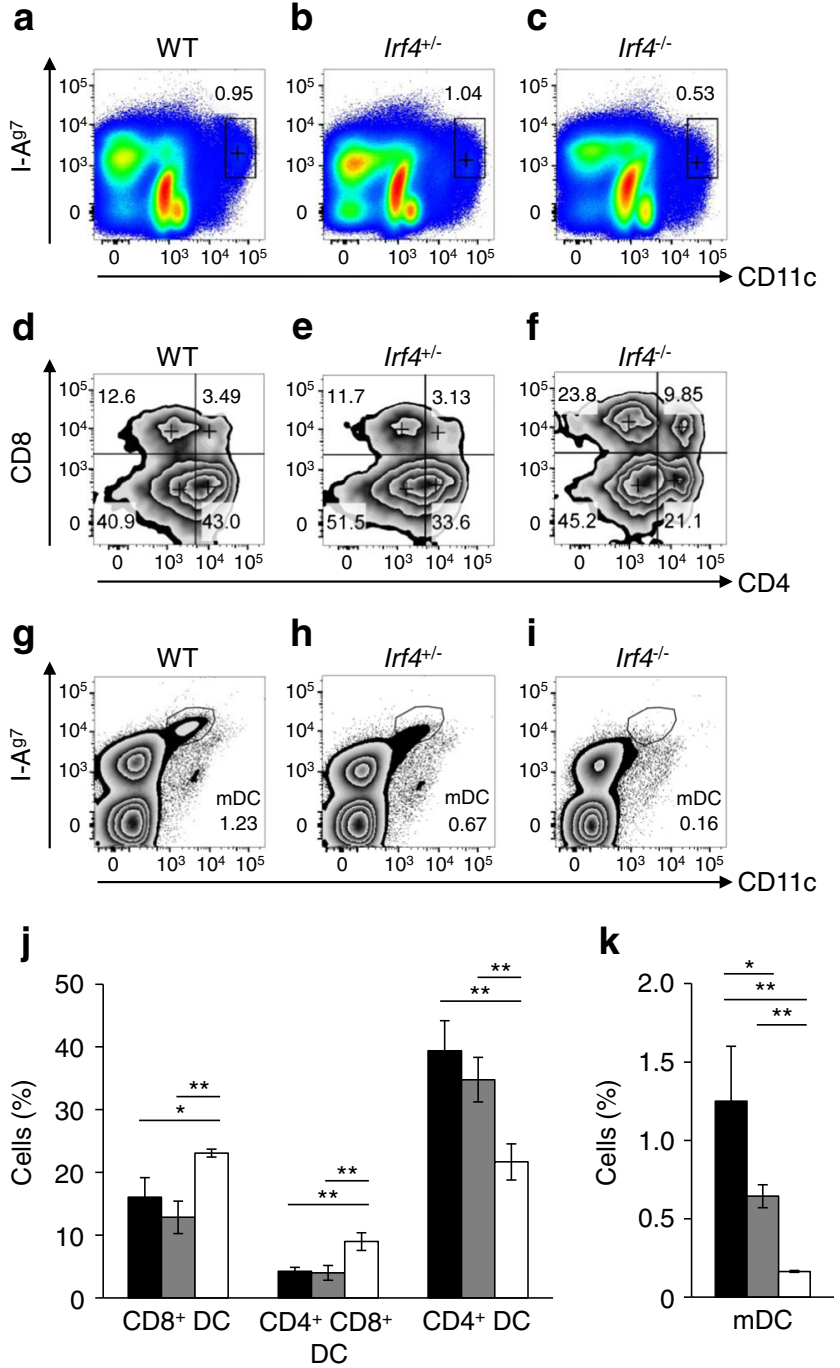

Fig. 6 DC subsets in spleen and peripheral lymph nodes. (a-f) SPCs were stained for CD11c, I-A ${ }^{\mathrm{g} 7}, \mathrm{CD} 4$ and CD8. (a-c) CD11c/I-A ${ }^{\mathrm{g} 7}$ profiles and $(\mathbf{d}-\mathbf{f}) \mathrm{CD} 4 / \mathrm{CD} 8$ profiles of DCs $\left(\mathrm{CD} 11 \mathrm{c}^{+} \mathrm{I}-\mathrm{A}^{\mathrm{g} 7+}\right)$. The numbers in the profiles indicate the proportions in the square $(\mathbf{a}-\mathbf{c})$ or in each quadrant (d-f). ( $\mathbf{g}-\mathbf{i})$ Cells from inguinal lymph nodes were stained for CD11c and I-A $\mathrm{A}^{\mathrm{g} 7}$, and the proportions (\%) of mDCs (I-A $\left.\mathrm{A}^{\mathrm{g} 7 \mathrm{hi}} \mathrm{CD} 11 \mathrm{c}^{\mathrm{int}}\right)$ are indicated. Populations of DC subsets in (j) spleen and (k) inguinal lymph nodes of WT (black bars), Irf4 $4^{+-}$(grey bars) and $\mathrm{Irf4}^{-1-}$ (white bars) NOD littermates are summarised as means \pm SD $(n=3) .{ }^{*} p<0.05$, $* * p<0.01$

$\mathrm{Irf4}^{-/}$NOD mice. These phenotypes are consistent with a previous report of $\mathrm{Irf4}^{-/}$mice of non-NOD background [37].

Our adoptive transfer study with effector $\mathrm{Irf4}^{-1-} \mathrm{T}$ cells showed the complete suppression of diabetes in recipient mice. These findings indicate that total elimination of IRF4 in $\mathrm{T}$ and $\mathrm{B}$ cells leads to their dysregulated function and diminishment of the intrinsic effector function of $\mathrm{T}$ cells that is associated with the development of diabetes in NOD mice. Our findings also revealed that: (1) total elimination of IRF4 abrogated the expression of effector molecules of $\mathrm{CD}^{+} \mathrm{T}$ cells after stimulation; and (2) deletion of IRF4 in $\mathrm{CD}^{+} \mathrm{T}$ cells protected recipient mice from rapid progression of diabetes. These results indicate that the expression of IRF4 is indispensable not only in $\mathrm{CD}^{+} \mathrm{T}$ cells, but also in $\mathrm{CD} 8^{+}$ T cells, for the development of insulitis/diabetes in NOD mice.

Of note, $\mathrm{Irf4}^{+/-}$mice showed complete resistance against diabetes development in our study. This is the first report to identify the importance of haploinsufficiency of IRF4 for disease resistance in autoimmune disease. This finding is highly critical from a clinical point of view, as it suggests the importance of subtle differences in IRF4 expression due to gene polymorphisms such as SPII for disease development or activity in systemic lupus erythematosus [40]. Similar results have been demonstrated in studies of mitogen-inducible gene 6 protein in streptozotocin-induced diabetes and in our previous study of IL-17 in autoimmune thyroiditis in NOD-H2 $2^{\mathrm{h} 4}$ mice $[41,42]$.

Currently, IRF4 is considered to be a key component that translates TCR affinity or the strength of TCR signalling into the functions of activated $\mathrm{CD}^{+} \mathrm{T}$ cells, including their differentiation and expansion in a dose-dependent manner [20, 43]. Interestingly, this gene-dose effect was evident in IRF4haploinsufficient $\mathrm{CD}^{+} \mathrm{T}$ cells. When $\mathrm{Irf4}^{-/}, \operatorname{Irf4} 4^{+-}$and WT $\mathrm{CD}^{+} \mathrm{T}$ cells were transferred into the same mice and activated in vivo, clonal expansion was most robust in $\mathrm{Irf4}^{+/+} \mathrm{CD}^{+} \mathrm{T}$ cells, followed by if $r 4^{+/-}$and by $\mathrm{Irf4}^{-/-}$ $\mathrm{CD}^{+} \mathrm{T}$ cells [20]. Consistent with these data, our adoptive transfer study showed that IRF4 deficiency in effector T cells conferred disease resistance in recipient mice in a gene-dosedependent manner. These results suggest that the dosage of IRF4 affects the function of autoreactive $\mathrm{CD}^{+} \mathrm{T}$ cells, or possibly $\mathrm{CD}^{+} \mathrm{T}$ cells, which is associated with diabetes susceptibility in NOD mice.

Despite the partial deficit of diabetogenicity in $\operatorname{Irf} 4^{+/}$effector T cells, Irf4 ${ }^{+/-}$NOD mice did not develop diabetes, and the mechanisms behind this are not completely explained by defects in T cells. We therefore investigated the phenotype of DCs, since previous reports have demonstrated that lack of IRF4 impairs the development of $\mathrm{CD}^{-} \mathrm{CD} 11 \mathrm{~b}^{+} \mathrm{DCs}$ in the spleen [27, 28] and reduces the recruitment of mDCs to draining lymph nodes [29, 30]. Interestingly, haploinsufficiency of IRF4 did not affect the development of $\mathrm{CD}^{+}$DCs in the spleen, but did reduce the proportion of $\mathrm{mDCs}$ in lymph nodes. These results suggest that IRF4 deficiency impairs the migratory function of DCs to draining lymph nodes in a gene-dosedependent manner, and that this deficit in DC function could play a role in the complete disease resistance of $\mathrm{Irf4}^{+/-} \mathrm{NOD}$ mice.

Clinical intervention trials conducted with patients with recent-onset type 1 diabetes and using targeted immunotherapy to $\mathrm{T}$ and $\mathrm{B}$ cells have demonstrated transiently reserved residual insulin productivity [44-47], although the treatments did not appear to fundamentally alter the overall disease course. Our study of IRF4-deficient NOD mice clarifies the important role of IRF4 in regulating T cells, DCs and possibly 
other cells in the pathogenesis of autoimmune diabetes, and our results demonstrate that the partial elimination of IRF4 fully suppresses the development of insulitis/diabetes in NOD mice. All of these findings indicate that IRF4 could be an effective therapeutic target in autoimmune diabetes.

Acknowledgements We thank M. Motomura, Y. Ohyama, M. Tanaka, H. Kawachi and S. Chuganji (Nagasaki University, Nagasaki, Japan) for technical assistance.

Funding This study was supported by research grants from the Japan Society for the Promotion of Science (Nos 23791036 and 24591334).

Duality of interest The authors declare that there is no duality of interest related to this study.

Contribution statement All authors contributed to the conception and design of the study; acquisition, analysis and interpretation of data; and drafting and editing of the manuscript. All of the authors approved the final version of the manuscript. SA, MK and NA had full access to all of the data in the study and take responsibility for the integrity of the data and the accuracy of the data analysis.

\section{References}

1. Atkinson MA, Maclaren NK (1994) The pathogenesis of insulindependent diabetes mellitus. N Engl J Med 331:1428-1436

2. Bluestone JA, Herold K, Eisenbarth G (2010) Genetics, pathogenesis and clinical interventions in type 1 diabetes. Nature 464:12931300

3. Anderson MS, Bluestone JA (2005) The NOD mouse: a model of immune dysregulation. Annu Rev Immunol 23:447-485

4. Tamura T, Yanai H, Savitsky D, Taniguchi T (2008) The IRF family transcription factors in immunity and oncogenesis. Annu Rev Immunol 26:535-584

5. Matsuyama T, Grossman A, Mittrucker HW et al (1995) Molecular cloning of LSIRF, a lymphoid-specific member of the interferon regulatory factor family that binds the interferon-stimulated response element (ISRE). Nucleic Acids Res 23:2127-2136

6. Biswas PS, Bhagat G, Pernis AB (2010) IRF4 and its regulators: evolving insights into the pathogenesis of inflammatory arthritis? Immunol Rev 233:79-96

7. Huber M, Lohoff M (2014) IRF4 at the crossroads of effector T cell fate decision. Eur J Immunol 44:1886-1895

8. Glasmacher E, Agrawal S, Chang AB et al (2012) A genomic regulatory element that directs assembly and function of immunespecific AP-1-IRF complexes. Science 338:975-980

9. Li P, Spolski R, Liao W et al (2012) BATF-JUN is critical for IRF4mediated transcription in T cells. Nature 490:543-546

10. Murphy TL, Tussiwand R, Murphy KM (2013) Specificity through cooperation: BATF-IRF interactions control immune-regulatory networks. Nat Rev Immunol 13:499-509

11. Rengarajan J, Mowen KA, McBride KD, Smith ED, Singh H, Glimcher LH (2002) Interferon regulatory factor 4 (IRF4) interacts with NFATc2 to modulate interleukin 4 gene expression. J Exp Med 195:1003-1012

12. Lohoff M, Mittrucker HW, Prechtl S et al (2002) Dysregulated T helper cell differentiation in the absence of interferon regulatory factor 4. Proc Natl Acad Sci U S A 99:11808-11812
13. Tominaga N, Ohkusu-Tsukada K, Udono H, Abe R, Matsuyama T, Yui K (2003) Development of Th1 and not Th2 immune responses in mice lacking IFN-regulatory factor-4. Int Immunol 15:1-10

14. Staudt V, Bothur E, Klein M et al (2010) Interferon-regulatory factor 4 is essential for the developmental program of $\mathrm{T}$ helper 9 cells. Immunity 33:192-202

15. Brustle A, Heink S, Huber M et al (2007) The development of inflammatory $\mathrm{T}(\mathrm{H})-17$ cells requires interferon-regulatory factor 4. Nat Immunol 8:958-966

16. Huber M, Brustle A, Reinhard K et al (2008) IRF4 is essential for IL-21-mediated induction, amplification, and stabilization of the Th17 phenotype. Proc Natl Acad Sci U S A 105:20846-20851

17. Bollig N, Brustle A, Kellner K et al (2012) Transcription factor IRF4 determines germinal center formation through follicular Thelper cell differentiation. Proc Natl Acad Sci U S A 109:86648669

18. Yao S, Buzo BF, Pham D et al (2013) Interferon regulatory factor 4 sustains $\mathrm{CD} 8^{+} \mathrm{T}$ cell expansion and effector differentiation. Immunity 39:833-845

19. Raczkowski F, Ritter J, Heesch K et al (2013) The transcription factor interferon regulatory factor 4 is required for the generation of protective effector $\mathrm{CD}^{+}$T cells. Proc Natl Acad Sci U S A 110: 15019-15024

20. Man K, Miasari M, Shi W et al (2013) The transcription factor IRF4 is essential for TCR affinity-mediated metabolic programming and clonal expansion of T cells. Nat Immunol 14:1155-1165

21. Cretney E, Xin A, Shi W et al (2011) The transcription factors Blimp-1 and IRF4 jointly control the differentiation and function of effector regulatory T cells. Nat Immunol 12:304-311

22. Ochiai K, Maienschein-Cline M, Simonetti G et al (2013) Transcriptional regulation of germinal center B and plasma cell fates by dynamical control of IRF4. Immunity 38:918-929

23. Johnson K, Hashimshony T, Sawai CM et al (2008) Regulation of immunoglobulin light-chain recombination by the transcription factor IRF-4 and the attenuation of interleukin-7 signaling. Immunity 28:335-345

24. Sciammas R, Shaffer AL, Schatz JH, Zhao H, Staudt LM, Singh H (2006) Graded expression of interferon regulatory factor-4 coordinates isotype switching with plasma cell differentiation. Immunity 25:225-236

25. Klein U, Casola S, Cattoretti G et al (2006) Transcription factor IRF4 controls plasma cell differentiation and class-switch recombination. Nat Immunol 7:773-782

26. Willis SN, Good-Jacobson KL, Curtis J et al (2014) Transcription factor IRF4 regulates germinal center cell formation through a B cell-intrinsic mechanism. J Immunol 192:3200-3206

27. Suzuki S, Honma K, Matsuyama T et al (2004) Critical roles of interferon regulatory factor 4 in $\mathrm{CD} 11 \mathrm{~b}^{\text {high }} \mathrm{CD} 8 \alpha^{-}$dendritic cell development. Proc Natl Acad Sci U S A 101:8981-8986

28. Tamura T, Tailor P, Yamaoka $\mathrm{K}$ et al (2005) IFN regulatory factor-4 and -8 govern dendritic cell subset development and their functional diversity. J Immunol 174:2573-2581

29. Akbari M, Honma K, Kimura D et al (2014) IRF4 in dendritic cells inhibits IL-12 production and controls Th1 immune responses against Leishmania major. J Immunol 192:2271-2279

30. Bajana S, Roach K, Turner S, Paul J, Kovats S (2012) IRF4 promotes cutaneous dendritic cell migration to lymph nodes during homeostasis and inflammation. J Immunol 189:3368-3377

31. Mudter J, Amoussina L, Schenk M et al (2008) The transcription factor IFN regulatory factor-4 controls experimental colitis in mice via T cell-derived IL-6. J Clin Invest 118:2415-2426

32. Lech M, Weidenbusch M, Kulkarni OP et al (2011) IRF4 deficiency abrogates lupus nephritis despite enhancing systemic cytokine production. J Am Soc Nephrol 22:1443-1452

33. Biswas PS, Gupta S, Chang E et al (2010) Phosphorylation of IRF4 by ROCK2 regulates IL-17 and IL-21 production and the 
development of autoimmunity in mice. J Clin Invest 120:3280 3295

34. Biswas PS, Gupta S, Chang E, Bhagat G, Pernis AB (2011) Aberrant ROCK activation promotes the development of type I diabetes in NOD mice. Cell Immunol 266:111-115

35. Joseph J, Bittner S, Kaiser FM, Wiendl H, Kissler S (2012) IL-17 silencing does not protect nonobese diabetic mice from autoimmune diabetes. J Immunol 188:216-221

36. Kuriya G, Uchida T, Akazawa S et al (2013) Double deficiency in IL-17 and IFN- $\gamma$ signalling significantly suppresses the development of diabetes in the NOD mouse. Diabetologia 56:1773-1780

37. Mittrucker HW, Matsuyama T, Grossman A et al (1997) Requirement for the transcription factor LSIRF/IRF4 for mature $\mathrm{B}$ and T lymphocyte function. Science 275:540-543

38. Serreze DV, Chapman HD, Varnum DS et al (1996) B lymphocytes are essential for the initiation of T cell-mediated autoimmune diabetes: analysis of a new "speed congenic" stock of NOD. Ig $\mu^{\text {null }}$ mice. J Exp Med 184:2049-2053

39. Yu L, Robles DT, Abiru N et al (2000) Early expression of antiinsulin autoantibodies of humans and the NOD mouse: evidence for early determination of subsequent diabetes. Proc Natl Acad Sci U S A 97:1701-1706

40. Hikami K, Kawasaki A, Ito I et al (2011) Association of a functional polymorphism in the 3 '-untranslated region of SPI1 with systemic lupus erythematosus. Arthritis Rheum 63:755-763
41. Ahyi AN, Chang HC, Dent AL, Nutt SL, Kaplan MH (2009) IFN regulatory factor 4 regulates the expression of a subset of Th2 cytokines. J Immunol 183:1598-1606

42. Horie I, Abiru N, Nagayama Y et al (2009) T helper type 17 immune response plays an indispensable role for development of iodine-induced autoimmune thyroiditis in nonobese diabetic- $\mathrm{H} 2^{\mathrm{h} 4}$ mice. Endocrinology 150:5135-5142

43. Nayar R, Schutten E, Bautista B et al (2014) Graded levels of IRF4 regulate $\mathrm{CD} 8^{+} \mathrm{T}$ cell differentiation and expansion, but not attrition, in response to acute virus infection. J Immunol 192: 5881-5893

44. Keymeulen B, Vandemeulebroucke E, Ziegler AG et al (2005) Insulin needs after CD3-antibody therapy in new-onset type 1 diabetes. N Engl J Med 352:2598-2608

45. Keymeulen B, Walter M, Mathieu C et al (2010) Four-year metabolic outcome of a randomised controlled CD3-antibody trial in recent-onset type 1 diabetic patients depends on their age and baseline residual beta cell mass. Diabetologia 53:614-623

46. Orban T, Bundy B, Becker DJ et al (2014) Costimulation modulation with abatacept in patients with recent-onset type 1 diabetes: follow-up 1 year after cessation of treatment. Diabetes Care 37: 1069-1075

47. Pescovitz MD, Greenbaum CJ, Bundy B et al (2014) B-lymphocyte depletion with rituximab and beta-cell function: two-year results. Diabetes Care 37:453-459 